\title{
Novel simple templates for reproducible positioning of skin applicators in brachytherapy
}

\author{
Silvia Rodríguez Villalba, MD!, Maria Jose Perez-Calatayud, MD², Juan Antonio Bautista, MSc², Vicente Carmona, MSc², \\ Francisco Celada, MD², Alejandro Tormo, MD², Teresa Garcia-Martinez, MSc'3 José Richart, MSc! \\ Manuel Santos Ortega, MD!, Magda Silla, MD , Facundo Ballester, PhD5, Jose Perez-Calatayud, PhDl.2 \\ 'Radiotherapy Department, Clínica Benidorm, Benidorm, ${ }^{2}$ Radiotherapy Department, La Fe University and Polytechnic Hospital, Valencia, \\ ${ }^{3}$ Radiotherapy Department, La Ribera University Hospital, Alzira, ${ }^{4}$ Dermatology Department, Clínica Benidorm, Benidorm, \\ ${ }^{5}$ Department of Atomic, Molecular, and Nuclear Physics, University of Valencia, Burjassot, Spain
}

\begin{abstract}
Purpose: Esteya and Valencia surface applicators are designed to treat skin tumors using brachytherapy. In clinical practice, in order to avoid errors that may affect the treatment outcome, there are two issues that need to be carefully addressed. First, the selected applicator for the treatment should provide adequate margin for the target, and second, the applicator has to be precisely positioned before each treatment fraction. In this work, we describe the development and use of a new acrylic templates named Template La Fe-ITIC. They have been designed specifically to help the clinical user in the selection of the correct applicator, and to assist the medical staff in reproducing the positioning of the applicator. These templates are freely available upon request.

Material and methods: Templates that were developed by University and Polytechnic Hospital La Fe (La Fe) and Hospital Clínica Benidorm (ITIC) in cooperation with Elekta, consist of a thin sheet made of transparent acrylic. For each applicator, a crosshair and two different circles are drawn on these templates: the inner one corresponds to the useful beam, while the outer one represents the external perimeter of the applicator. The outer circle contains slits that facilitate to draw a circle on the skin of the patient for exact positioning of the applicator. In addition, there are two perpendicular rulers to define the adequate margin. For each applicator size, a specific template was developed.

Results: The templates have been used successfully in our institutions for more than 50 patients' brachytherapy treatments. They are currently being used for Esteya and Valencia applicators.

Conclusions: The template La Fe-ITIC is simple and practical. It improves both the set-up time and reproducibility. It helps to establish the adequate margins, an essential point in the clinical outcome.
\end{abstract}

J Contemp Brachytherapy 2016; 8, 4: 344-348

DOI: 10.5114/jcb.2016.61713

Key words: brachytherapy, electronic brachytherapy, skin applicators, skin cancer, template.

\section{Purpose}

Non melanoma skin cancer is one of the most common cancers in humans [1]. Surgery, topic agents, cryotherapy, electrodessication, and curettage are among the treatment options. Nowadays, brachytherapy techniques play an increasingly relevant role. Different modalities of skin brachytherapy include superficial treatments, custom molds, flap applicators, radionuclide based applicators as Leipizg (Varian Medical Systems, Palo Alto, CA, USA and Nucletron, an Elekta company, Elekta AB, Stockholm, Sweden) or Valencia (Elekta), and electronic brachytherapy as Axxent (Xoft Inc., San Jose, CA, USA), the Intrabeam (Carl Zeiss, Oberkochen, Germany) and the Esteya (Elekta) [2]. All of them are used for brachytherapy as a primary or adjuvant (affected close margins) treatment modality reaching excellent control rates, cosmetic results, and improvement in quality of life $[3,4,5,6,7,8,9]$. All macroscopic lesions/surgical bed must be included in the treatment field with adequate margins; these margins vary depending on histology of the lesion to be treated $(5-10 \mathrm{~mm})$ [2]. The Valencia applicators are cup-shaped and made of tungsten, which allows applying a high dose to the malignant tissue whilst protecting surrounding healthy tissue from radiation damage $[5,10]$. These applicators are available with 2 and $3 \mathrm{~cm}$ in diameter of useful beam, and are used for a typical prescription depth of 3-4 $\mathrm{mm}$.

One of the clinically available electronic brachytherapy system is Esteya $[11,12,13,14]$. This system consists of an electronical X-ray, which provides advantages in the treatment time and radiation protection shielding component. It has $69.5 \mathrm{kVp}$ and its gradient is slightly smaller
Address for correspondence: Silvia Rodriguez Villalba, MD, Hospital Clínica Benidorm, Radiotherapy Department, Avenida Alfonso Puchades 8, 03501 Benidorm, Alicante, Spain, phone: +34 606557346; +34 966072725, fax: +34 9966072724, 凶 e-mail: srodriguez@clinicabenidorm.com
Received: 26.05 .2016

Accepted: 18.07 .2016

Published: 24.08.2016 
( $8 \%$ per $\mathrm{mm}$ ) than the one for the Valencia ( $12 \%$ per $\mathrm{mm})$ [2]. Tungsten made applicators are available in sizes 1 to $3 \mathrm{~cm}$ in diameter. Valencia and Esteya applicators are designed to be used for areas where full contact with the surface to be treated is possible. They must be fixed by using some pressure to homogenize the skin surface, assuring full contact between skin and applicator surface. Immobilization of both, the applicator and patient, are important and should be performed for each treatment fraction.

A crucial issue in a successful skin treatment is the reproducible positioning of the applicator in exactly the same location over the course of each treatment fraction, since centering the applicator over the lesion is difficult [15]. The purpose of this work is to describe the transparent acrylic template named La Fe-ITIC Template, and its use. These templates have been designed specifically to assist the positioning of the aforementioned applicators over skin cancer lesions. They are also used to select the appropriate applicator size according to the planning target volume (PTV) and margin to help when interfraction set-up is required.

In our institutions, brachytherapy treatments have been performed using both Valencia applicators and the Esteya.
In both cases, excellent results have been achieved as it has been reported in the literature $[5,16,17]$. While these templates were briefly described previously by our group [11], this manuscript will provide a thorough description that includes a version for the Valencia applicators. The authors are willing to make these templates available upon request without charge, to Valencia and Esteya users.

\section{Material and methods}

These templates consist of a thin sheet of transparent acrylic. A crosshair and two different circles are drawn for each applicator. The inner one corresponds to the useful beam, while the outer one represents the external perimeter of the applicator. The outer circle contains slits that facilitates drawing a circle on the patient's skin for accurate positioning of the applicator. For each applicator size, a specific template was developed (Figure 1).

In addition, there are two perpendicular rulers, graduated in $\mathrm{mm}$, to help in margin evaluation. For each applicator size ( 5 sizes for the Esteya system and 2 sizes for the Valencia applicators), a specific template was developed. All of them are properly labelled with the corresponding specific system and applicator size.
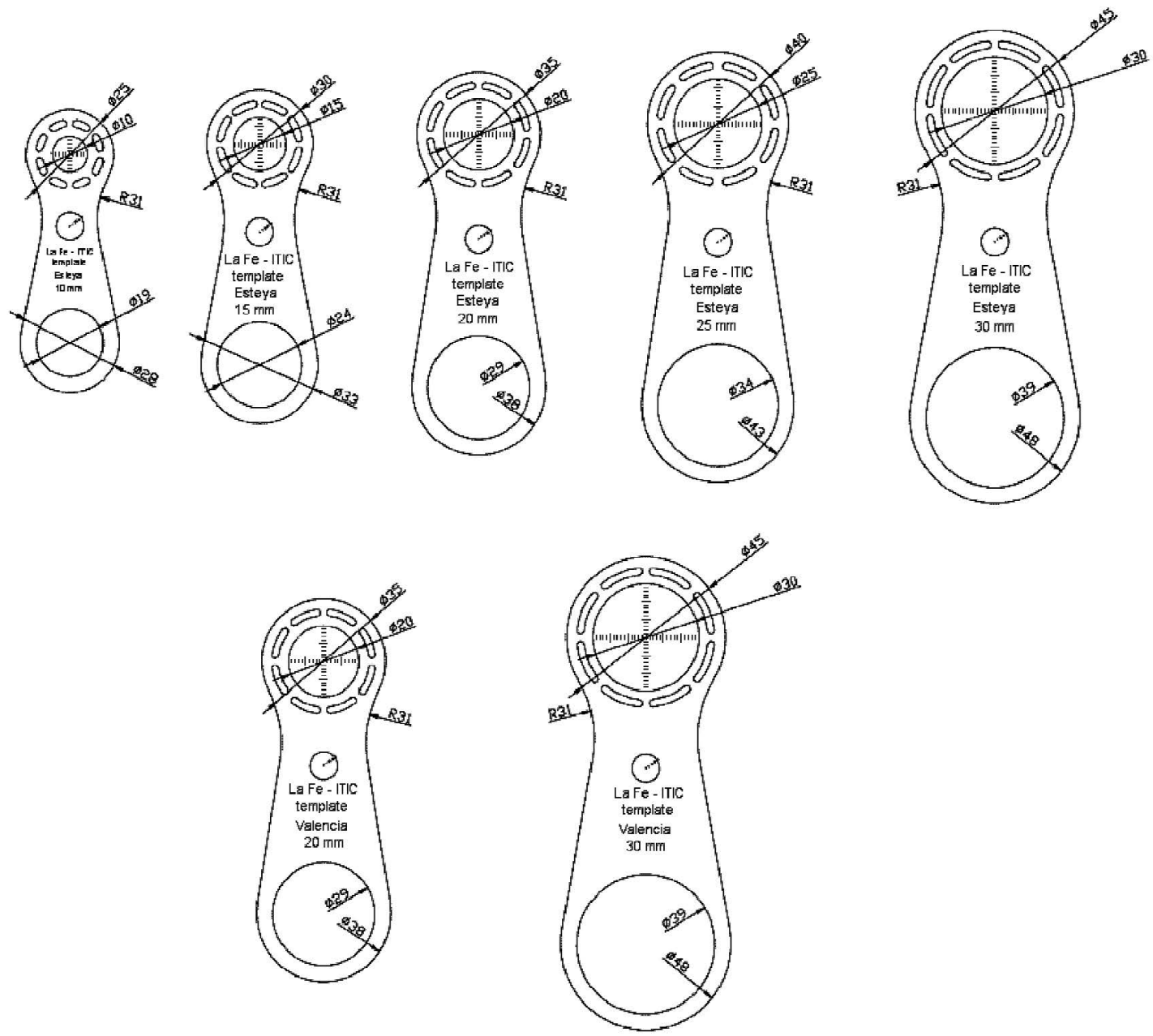

Fig. 1. Illustration of the templates design. Upper row: templates for the Esteya applicators ( 5 sizes). Lower row: templates for the Valencia applicator (2 sizes) 
The procedure to use the templates is as follows: once the depth is evaluated [18], the gross tumor volume (GTV) is drawn, typically using a dermatoscope in macroscopic disease [19]. With the help of the graduated rulers, it is possible to select the applicator size according to the required margin taking into account the useful beam (area in which the dose is uniform, keeping out the penumbra). Once selected, the outer circle in grooves is drawn on the skin to help in the set-up of each fraction, matching this circle with the outer circumference of the applicator plus $1 \mathrm{~mm}$ (Figure 2). It facilitates the applicator set-up in each fraction. The extra $1 \mathrm{~mm}$ enables the view of proper fitting of the applicator.

\section{Results and discussion}

The developed templates have been successfully used in our institutions for the treatment of more than $50 \mathrm{pa}-$ tients with both Esteya electronic brachytherapy and Valencia applicators. Every template is specific for each applicator size. The patient's lesion suitable for the contact applicators has to be very carefully selected to avoid the failure of healthy tissue as a margin. All surface applicators must be used in direct contact with the skin. Figure 3
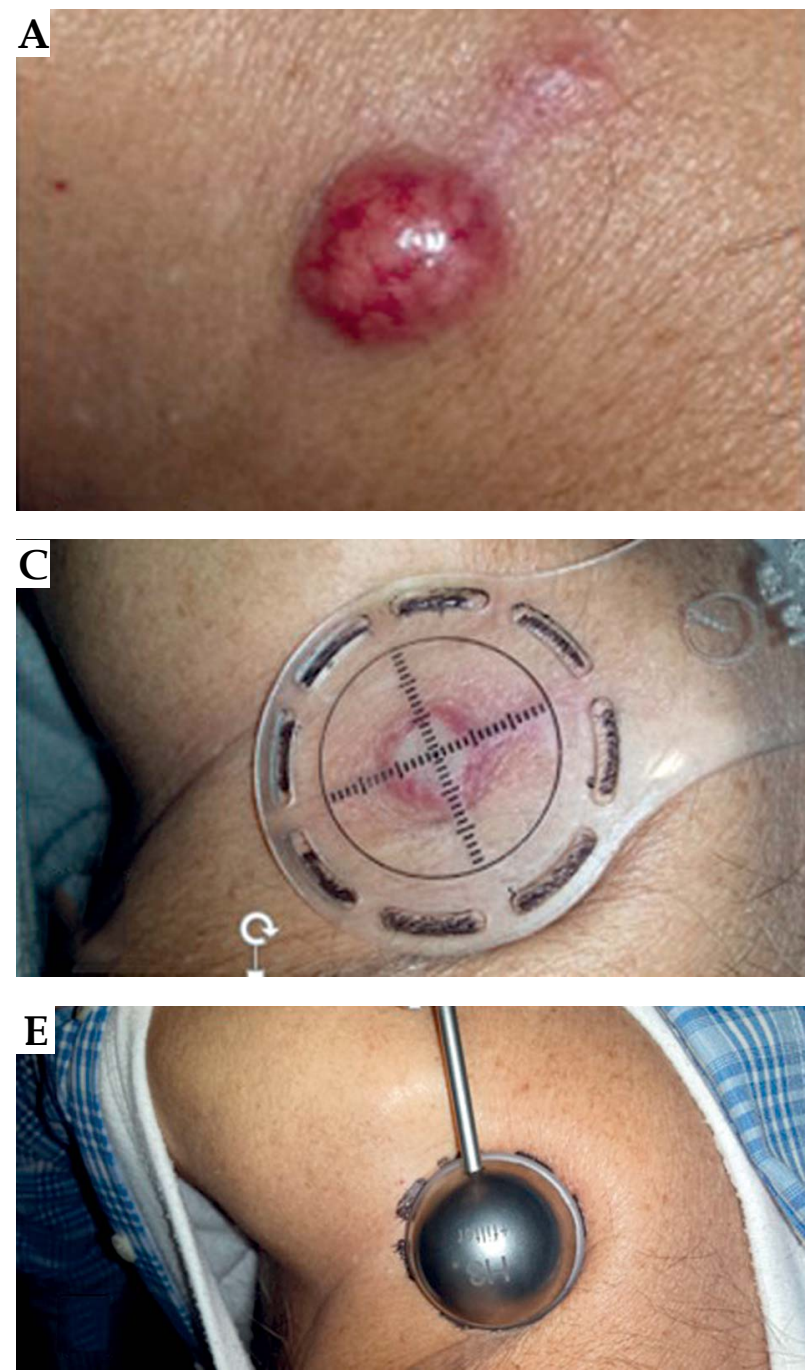

shows a clear case where the Valencia applicators are not indicated due to height of the keratosis lesion that does not allow to apply the applicator in full and homogeneous contact with the skin.

The Valencia applicators are provided with two removable plastic caps ( $1 \mathrm{~mm}$ thick). One of them is flat and used during treatments. The one with the ring is usually applied for simulation purpose. By gentle pressure of this cap on the patient's skin, a circumference will be visible over the skin surface showing the useful beam of the applicator. In our institutions, the Valencia applicators are used always with the same plastic cap (with no ring) surrounding the applicator with a stressed latex cover to prevent contamination between patients. In case of Esteya, a plastic film is used between applicator and patient skin.

Plastic cap must always be used and kept during treatment to avoid overdosage and skin complications. The cap is also included as a build-up region to reach electronic equilibrium and to absorb the secondary electrons generated in the applicator. The dose differences due to treatment with and without the cap are undesirably large for the first millimeter of skin (up to a factor of 2.8) [20]. Therefore, the outer circle of the Templates La Fe-ITIC
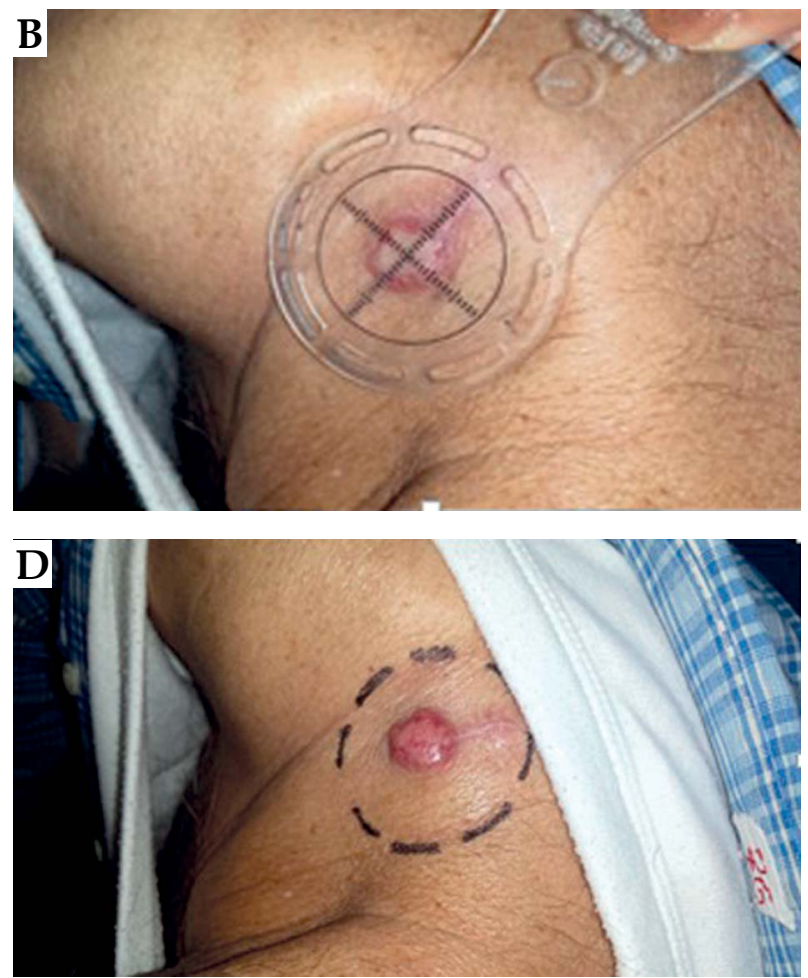

Fig. 2. Illustration of the marking and set-up procedure for the case of the Valencia applicator. A) Lesion. B) Selected size of applicator to ensure adequate margins. C) and D) Draws in skin of outer diameter of applicator. E) Circle painted in skin facilitating the reproducibility in each fraction of applicator, in this case the Valencia $3 \mathrm{~cm}$ size 

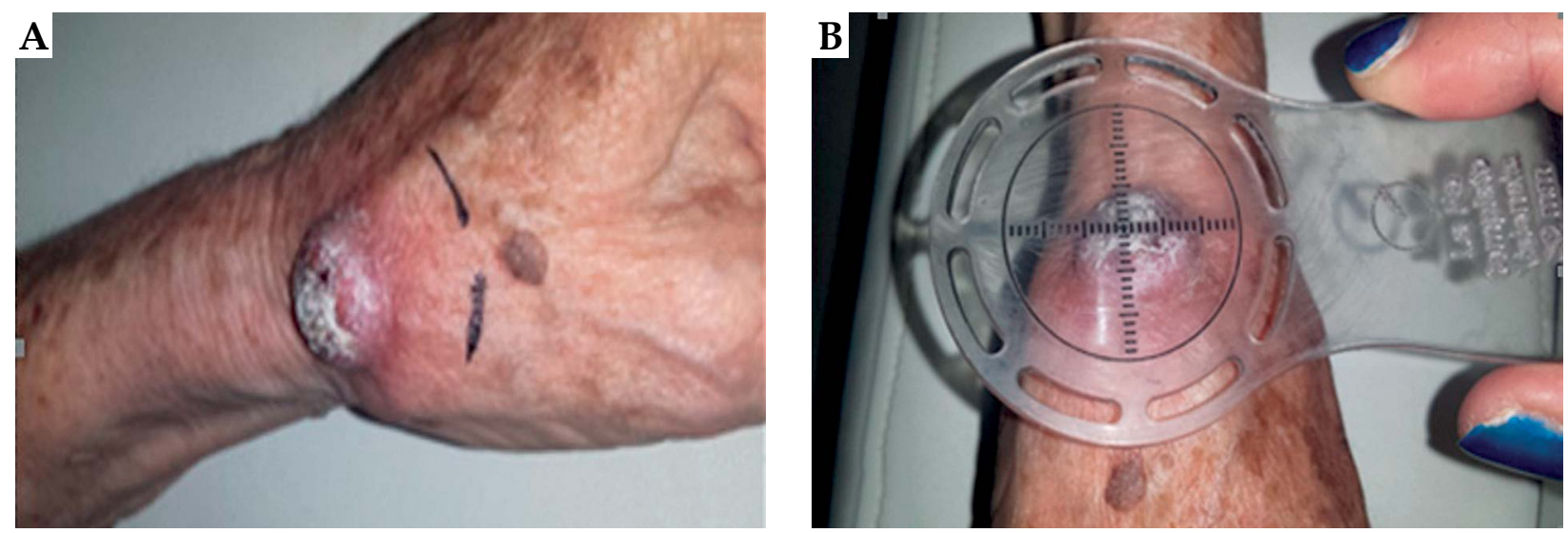

Fig. 3. Case not indicated for surface applicators. A) Lesion. B) Template La FE-ITIC cannot be in contact with skin

for the Valencia applicators is defined with the plastic cap in place.

Recently, a new Valencia applicator model has been developed [21]. These are able to cover a field up to $5 \mathrm{~cm}$ in diameter. Because this applicator will also be used in direct contact with the skin, similar templates will be developed. The template can be easily cleaned to prevent crosscontamination between patients. These has not shown any problem after using them for two years. As discussed in the ABS report [2], the PTV versus clinical target volume (CTV) issue has been controversial in brachytherapy. It seems logical that in an interstitial implant, the PTV equals the CTV. Nevertheless, an expansion from CTV to PTV is required in the case of superficial lesions due to potential variations in the set-up. Therefore, in order to ensure adequate dose coverage, an additional setup margin from CTV to PTV should be established. In our opinion, with the help of the templates and procedures described in this work, an extra margin of $1 \mathrm{~mm}$ should be sufficient. This CTV to PTV margin must be considered in the applicator size selection with the help of the graduated rulers incorporated at the La Fe-ITIC Templates.

\section{Conclusions}

The developed template La Fe-ITIC is simple and practical. It improves both the set-up time and the reproducibility. It helps the clinical user to establish the adequate margins, which are an essential point in the clinical outcome. Authors want to make it available by request and without charge to the brachytherapy community of Elekta users: joseperezcalatayud@gmail.com.

\section{Acknowledgments}

The study was supported in part by Generalitat Valenciana under Project PROMETEOII/2013/010 and by Spanish Government under Project No FIS2013-42156.

\section{Disclosure}

Authors report no conflict of interest.

\section{References}

1. Lear W, Dahlke E, Murray CA. Basal cell carcinoma: review of epidemiology, pathogenesis, and associated risk factors. J Cutan Med Surg 2007; 11: 19-30.

2. Ouhib Z, Kasper M, Perez-Calatayud J et al. Aspects of dosimetry and clinical practice of skin brachytherapy: The American Brachytherapy Society working group report. Brachytherapy 2015; 14: 840-858.

3. Köhler-Brock A, Prager W, Pohlmann S et al. The indications for and results of HDR afterloading therapy in diseases of the skin and mucosa with standardized surface applicators (the Leipzig Applicator). Strahlenther Onkol 1999; 175: 170-174 [Article in German].

4. Guix B, Finestres F, Tello J et al. Treatment of skin carcinomas of the face by high dose rate brachytherapy and custom made surface molds. Int J Radiat Oncol Biol Phys 2000; 47: 95-102.

5. Tormo A, Celada F, Rodriguez $\mathrm{S}$ et al. Non-melanoma skin cancer treated with HDR Valencia applicator: clinical outcomes. J Contemp Brachytherapy 2014; 6: 167-172.

6. Montero A, Hernan R, Capuz A et al. High-dose-rate (HDR) plesiotherapy with custom-made mold for the treatment of non- melanoma skin cancer. Clin Transl Oncol 2009; 11: 760-764.

7. Skowronek J. Brachytherapy in the treatment of skin cancer: an overview. Postepy Dermatol Alergol 2015; 32: 362-367.

8. Delishaj D, Laliscia C, Manfredi B et al. Non-melanoma skin cancer treated with high-dose rate brachytherapy and Valencia applicator in elderly patients: a retrospective case series. J Contemp Brachytherapy 2015; 7: 437-444.

9. Bhatnagar A. Non-melanoma skin cancer treated with electronic brachytherapy: results at 1 year. Brachytherapy 2013; 12: 134-140.

10. Granero D, Perez-Calatayud J, Gimeno J et al. Design and evaluation of a HDR skin applicator flattening filter. Med Phys 2008; 35: 495-503.

11. Pons-Llanas O, Ballester-Sánchez R, Celada-Álvarez FJ et al. Clinical implementation of a new electronic brachytherapy system for skin brachytherapy. J Contemp Brachytherapy 2015; 6: 417-423.

12. Candela-Juan C, Vijande J, García-Martínez T et al. Comparison and uncertainty evaluation of different calibration protocols and ionization chambers for low-energy surface brachytherapy dosimetry. Med Phys 2015; 42: 4954-4964.

13. Candela-Juan C, Niatsetski Y, Ouhib Z et al. Commissioning and periodic test of the Esteya electronic brachytherapy system. J Contemp Brachytherapy 2015; 7: 189-195.

14. Garcia-Martinez T, Chan J-P, Perez-Calatayud J et al. Dosimetric characteristics of a new unit for electronic skin brachytherapy. J Contemp Brachytherapy 2014; 6: 1-9. 
15. Sayler E, Eldredge-Hindy H, Dinome J et al. Clinical implementation and failure and effects analysis of HDR skin brachytherapy using Valencia and Leipzig surface applicators. Brachytherapy 2015; 14: 293-299.

16. Ballester-Sánchez R, Pons-Llanas O, Candela-Juan C et al. Efficacy and safety of electronic brachytherapy for superficial and nodular basal cell carcinoma. J Contemp Brachytherapy 2015; 7: 1-8.

17. Ballester-Sánchez R, Pons-Llanas O, Candela C et al. Electronic brachytherapy for superficial and nodular basal cell carcinoma: a report of two prospective pilot trials using different doses. J Contemp Brachytherapy 2016; 8: 48-55.

18. Ballester-Sánchez R, Pons-Llanas O, Llavador-Ros $\mathrm{M}$ et al. Depth determination of skin cancers treated with superficial brachytherapy: ultrasound vs. histopathology. J Contemp Brachytherapy 2014; 4: 356-361.

19. Ballester-Sánchez R, Pons-Llanas O, Pérez-Calatayud J et al. Dermoscopy margin delineation in radiotherapy planning for superficial or nodular basal cell carcinoma. Br J Dermatol 2014; 172: 1162-1163.

20. Granero D, Candela-Juan C, Vijande J et al. Dosimetry of Leipzig and Valencia applicators without the plastic cap. Med Phys 2016; 43: 2087.

21. Candela-Juan C, Niatsetski Y, van der Laarse R et al. Design and characterization of a new high-dose-rate brachytherapy Valencia applicator for larger skin lesions. Med Phys 2016; 43 : 1639-1648. 